\title{
SEDIMENTANDO AS BASES DE UM CONCEITO: AS COMPETÊNCIAS EMPREENDEDORAS
}

\author{
Márcia Aparecida Zampier ${ }^{1}$ \\ PPAD/UFPR \\ Adriana Roseli Wunsch Takahashi \\ PPAD/UFPR \\ Bruno Henrique Fernandes ${ }^{3}$ \\ PMDA/ UP
}

\begin{abstract}
Resumo: O tema das competências tem estado em evidência na literatura sobre empreendedorismo. No entanto, a apropriação do conceito carece de maiores discussões, sendo conveniente restabelecer e reforçar algumas conexões que o campo deve manter com as temáticas que lhe fornecem base interpretativa. Nesse sentido, o presente artigo tem o objetivo de revisitar as noções correntes adotadas para o conceito de competências na área de empreendedorismo, aportar as discussões acerca de competências em outros campos, e propor uma base terminológica que possa auxiliar esforços de pesquisa subsequentes voltados a competências empreendedoras. Para a consecução deste objetivo, são demonstrados: conceito de competências, competências empreendedoras e tipologias associadas. Após revisar estudos abordando a noção de competência em seu mainstream na área de negócios - notadamente, o campo de gestão de pessoas - volta-se à análise do uso que se faz do conceito de competências empreendedoras. Observa-se que, neste campo, frequentemente se tomam noções como atitudes, traços de personalidade ou valores pessoais como sinônimos de competência. Tal nivelamento pode obscurecer 0 entendimento das pesquisas realizadas sobre o tema de competências empreendedoras.
\end{abstract}

Palavras-chave: Empreendedorismo, competências, competências empreendedoras.

\section{SEDIMENTING THE BASIS OF A CONCEPT: THE ENTREPRENEURIAL COMPETENCIES}

Abstract: The issue of competency has been in evidence in the literature on entrepreneurship. However, the appropriation of the concept needs further discussion, being appropriate to restore and strengthen some connections with original areas that will help providing interpretive basis. Accordingly, this article aims to revisit the current notions taken to the concept of entrepreneurial competencies, contribute to discussions about the competency in other fields, and propose a terminology basis that can help subsequent research efforts aimed at competency entrepreneurs. To achieve this goal, are demonstrated: the concept of competencies, entrepreneurial competencies and its associated types. After reviewing studies

\footnotetext{
${ }^{1}$ Endereço: Rua Barão de Capanema, 70 - Bloco 6, Apto, 11. Bairro Santa Cruz. Guarapuava/PR.

2 Endereço: Rua José Cadilhe, n. 1246 Curitiba/PR.

${ }^{3}$ Endereço: Rua Prof. Pedro Viriato Parigot de Souza, 5300. CEP - 81280-330. Curitiba /PR.
} 
addressing the notion of competency in business literature mainstream - notably, the field of human resources - the analysis focuses in the use of entrepreneurial competencies. Often, in this field, concepts such as attitudes, personality traits or personal values are taken as synonymous with competency. This leveling can obscure the understanding of the research on the topic of entrepreneurial competencies.

Keywords: Entrepreneurship, competencies, entrepreneurial competencies.

\section{INTRODUÇÃO}

O tema das competências empreendedoras vem recebendo destaque na literatura em empreendedorismo nos últimos anos (MAMEDE; MOREIRA, 2005; MAN; LAU, 2000; SNELL; LAU, 1994; ANTONELLO, 2005; BARON; SHANE, 2007; LEIRIA, 2002). O racional por trás da emergência do tema está na investigação de comportamentos que caracterizam uma atuação empreendedora e, neste sentido, vem se buscando no referencial de competências um suporte explicativo. Entretanto, observa-se que a apropriação do conceito de competências no campo do empreendedorismo, no Brasil e no exterior, ainda carece de maior rigor conceitual e, por extensão, instrumental. Nota-se que a abordagem de competências na área de empreendedorismo não absorveu discussões recentes abordadas no campo de competências, que tem sido foco de debates em áreas como estratégia, gestão de pessoas, relações do trabalho e educação. Constata-se aqui um aspecto recorrente nos estudos de empreendedorismo: por se constituir num campo interdisciplinar, de tempos em tempos convém restabelecer e reforçar algumas conexões que o campo deve manter com as temáticas que lhe fornecem base interpretativa para seus resultados. Este é o propósito deste ensaio: revisitar as noções correntes adotadas para o conceito de competências na área de empreendedorismo, aportar as discussões acerca de competências de outros campos, e propor uma base terminológica que possa auxiliar esforços de pesquisa subseqüentes voltados a competências empreendedoras.

Para cumprir esta agenda, o presente artigo se inicia revisando o conceito de competência em suas vertentes nas áreas de estratégia, gestão de pessoas e educação. A seguir, são apresentas algumas reflexões sobre competências no campo de empreendedorismo. Com base no conceito amplo de competências, analisa-se a abordagem adotada no campo de empreendedorismo. Por fim, propõe- 
se o nivelamento conceitual e diretrizes metodológicas para investigar o tema: competências empreendedoras.

\section{O CONCEITO DE COMPETÊNCIAS}

A origem do conceito no final da Idade Média estava associada à linguagem jurídica e dizia respeito à faculdade atribuída a alguém para apreciar e julgar certas questões. Posteriormente, passou a ser utilizado de forma mais genérica para qualificar 0 indivíduo capaz de realizar determinado trabalho (BRANDÃO; GUIMARÃES, 1999).

$\mathrm{Na}$ administração, desde os trabalhos de Taylor e Ford se percebe a preocupação com o estudo das competências, pois eles se preocupavam em identificar o indivíduo competente, ou seja, aquele que melhor desempenhasse suas tarefas (FLEURY; FLEURY, 2004).

$\mathrm{Na}$ década de 1970, foi McClelland quem realizou diversos estudos relacionados ao termo competências, e nos anos 80 do século $X X$ Boyatizis o explorou no contexto gerencial (BITENCOURT, 2005). A partir de então, o termo competências foi se desenvolvendo rapidamente e surgiram diversas correntes de estudos na literatura, dentre as quais Dutra et al. (2006) destacam: a) angloamericana, representada por McClelland (1972), Boyatizis (1994), Spencer e Spencer (1994) (MOURA; BITENCOURT, 2006) b) européia que tem como principais autores: Sandberg (1996), Zarifian (2001), Le Boterf (2003), MOURA; BITENCOURT, (2006).

Segundo Cheetham e Chivers (1996; 1998) e Gefroy e Tijou (2002), três abordagens predominantes são relacionadas nos estudos de competências:

a) Americana - na qual o foco são os elementos comportamentais ou os atributos individuais e a competência é vista como um estoque de recursos do indivíduo, ou seja, seus conhecimentos, habilidades e atitudes $(\mathrm{CHA})$.

b) Funcional (Inglaterra) - CHA identificado mediante análise funcional do desempenho e das responsabilidades assumidas pelo indivíduo e as competências vinculadas aos objetivos organizacionais. 
c) Construtivista (França) - analisa a competência como um processo dinâmico reconhecido pelos resultados da ação e trata da competência prática.

No Brasil, o tema de competências inspira-se nessas três vertentes, e é alvo de várias publicações. Exemplo disso é a síntese das principais publicações nacionais entre 2000 e 2004 sobre o conceito de competência realizada por Ruas et al. (2005). Os autores utilizaram uma amostra de 51 artigos científicos publicados na RAUSP, RAE-FGV, RAC, O\&S e ENANPAD. As instituições com o maior número de publicações respectivamente foram: FEA/USP (13), UFRGS (11), UFMG (10), UnB (6), UFBA (5) e os 20 autores mais citados como referências bibliográficas nas publicações foram:

Quadro 1 - Os 20 autores mais citados como referências bibliográficas - Competências

\begin{tabular}{|l|c|l|c|}
\hline \multicolumn{1}{|c|}{ Autor } & $\begin{array}{c}\text { Quantidade de } \\
\text { citações }\end{array}$ & \multicolumn{1}{|c|}{ Autor } & $\begin{array}{c}\text { Quantidade } \\
\text { de citações }\end{array}$ \\
\hline HAMEL, G. & 37 & NONAKA & 14 \\
\hline PRAHALAD, C. K. & 33 & TEECE, D. J. & 14 \\
\hline ZARIFIAN, P. & 33 & BOYATSIS, R. & 12 \\
\hline FLEURY, M. T. & 30 & HEENE, A. & 12 \\
\hline LE BOTERF, G. & 24 & ROPE, A. & 11 \\
\hline FLEURY, A C. & 21 & BARNEY, J. B. & 11 \\
\hline DUTRA, J. S. & 19 & BITTENCOURT, C. & 11 \\
\hline RUAS, R. & 18 & PORTER, M. E. & 10 \\
\hline TANGUY, L. & 16 & SPENCER, S. & 11 \\
\hline SPENCER, L. M. & 16 & SENGE, P. & . \\
\hline
\end{tabular}

Fonte: RUAS, R. et al. O conceito de competência de $\mathrm{A}$ a Z:análise e revisão nas principais publicações nacionais entre 2000 e 2004. In: ENCONTRO NACIONAL DA ASSOCIAÇÂO NACIONAL DE PÓS-GRADUAÇÃO E PESQUISA EM ADMINISTRAÇÃO, 29, 2005, Brasília. Anais...Rio de Janeiro: Anpad, 2005

Mais recentemente, Ruas et al (2009) realizaram nova revisão de artigos no tema, cobrindo periódicos Qualis A publicados entre 2000 e 2008. 
Tabela 1: Revisão de trabalhos sobre competências no Brasil 2000-2008

\begin{tabular}{cccccc}
\hline $\begin{array}{c}\text { Ano/ } \\
\text { Fonte }\end{array}$ & RAC & O\&S & RAUSP & RAE & TOTAIS \\
\hline 2000 & 1 & 1 & 0 & 2 & 4 \\
2001 & 0 & 0 & 1 & 1 & 2 \\
2002 & 1 & 1 & 0 & 1 & 4 \\
2003 & 3 & 1 & 2 & 3 & 4 \\
2004 & 1 & 0 & 0 & 1 & 8 \\
2005 & 3 & 3 & 1 & 2 & 4 \\
2006 & 1 & 1 & 0 & 1 & 6 \\
2007 & 2 & 3 & 0 & 0 & 5 \\
\hline 2008 & 3 & 0 & 2 & 13 & 44 \\
\hline TOTAL & 15 & 10 & 6 & 2 & 4 \\
\hline
\end{tabular}

Fonte: RUAS, R. et al. Gestão por competências: revisão de trabalhos acadêmicos no Brasil no período 2000 a 2008. Working paper, 2009

Os autores constatam que o tema competências vem sendo bastante abordado na produção científica no país no campo de gestão de pessoas, sendo que raras vezes as discussões travadas sobre esse tema extrapolam ou aplicam-se a outras áreas de estudo em gestão. Como resultado, observa-se uma desconexão entre o conceito de competências tal qual debatido no âmbito de gestão de pessoas (para o qual se observa uma tendência à convergência no país em torno do conceito de entrega, segundo Ruas et al, 2009) e aquele apropriado por outras áreas de estudo em Administração.

Diversas são as perspectivas mediante as quais o tema competências vem sendo tratado na literatura. Bitencourt (2005) apresenta uma seleção de conceitos com diferentes enfoques, de acordo com vários autores. 
Quadro 2 - Conceito de competências

\begin{tabular}{|c|c|c|}
\hline Autor (es) & Conceito & Ênfase \\
\hline $\begin{array}{l}\text { Boyatizis } \\
\text { (1982, p. 23) }\end{array}$ & $\begin{array}{l}\text { Competências são aspectos verdadeiros ligados à natureza } \\
\text { humana. São comportamentos observáveis que determinam, em } \\
\text { grande parte, o retorno da organização. }\end{array}$ & $\begin{array}{l}\text { Formação, } \\
\text { comportamentos e } \\
\text { resultados. }\end{array}$ \\
\hline $\begin{array}{l}\text { Spencer e } \\
\text { Spencer } \\
(1993, \text { p. 9) }\end{array}$ & $\begin{array}{l}\text { A competência refere-se a características intrínsecas do } \\
\text { indivíduo que influencia e serve de referencial para seu } \\
\text { desempenho no ambiente de trabalho. }\end{array}$ & $\begin{array}{l}\text { Formação e } \\
\text { resultado. }\end{array}$ \\
\hline $\begin{array}{l}\text { Le Boterf } \\
(2003, p \text {. } \\
267)\end{array}$ & $\begin{array}{l}\text { Competência é assumir responsabilidades em face das } \\
\text { situações de trabalho complexas, buscando lidar com eventos } \\
\text { inéditos, surpreendentes, de natureza singular. }\end{array}$ & $\begin{array}{l}\text { Mobilização e } \\
\text { ação. }\end{array}$ \\
\hline $\begin{array}{l}\text { Perrenoud } \\
(1999)\end{array}$ & $\begin{array}{l}\text { A noção de competência refere-se a práticas do quotidiano que } \\
\text { se mobilizam através do saber baseado no senso comum e do } \\
\text { saber a partir de experiências. }\end{array}$ & Formação e ação \\
\hline $\begin{array}{l}\text { Durand } \\
(1998, \text { p. 3) }\end{array}$ & $\begin{array}{l}\text { Conjuntos de conhecimentos, habilidades e atitudes } \\
\text { interdependentes e necessárias à consecução de determinado } \\
\text { propósito. }\end{array}$ & $\begin{array}{l}\text { Formação e } \\
\text { resultados }\end{array}$ \\
\hline $\begin{array}{l}\text { Dutra (2001, } \\
\text { p. 29) }\end{array}$ & $\begin{array}{l}\text { Competência está associada à noção de entrega, aquilo que a } \\
\text { pessoa pode e quer entregar à organização, portanto refere-se } \\
\text { ao indivíduo saber agir de maneira responsável e ser } \\
\text { reconhecido por isso. }\end{array}$ & $\begin{array}{l}\text { Aptidão, entrega e } \\
\text { formação. }\end{array}$ \\
\hline Ruas (2005) & $\begin{array}{l}\text { É a capacidade de mobilizar, integrar e colocar em ação } \\
\text { conhecimentos, habilidades e formas de atuar (recursos de } \\
\text { competências), a fim de atingir/superar desempenhos } \\
\text { configurados na missão da empresa e da área. }\end{array}$ & Ação e resultados. \\
\hline $\begin{array}{l}\text { Fleury e } \\
\text { Fleury } \\
(2004, \text { p. 30) }\end{array}$ & $\begin{array}{l}\text { Competência: um saber agir responsável e reconhecido, que } \\
\text { implica mobilizar, integrar, transferir conhecimentos, recursos, } \\
\text { habilidades, que agreguem valor econômico à organização e } \\
\text { valor social ao indivíduo. }\end{array}$ & Ação e resultado. \\
\hline $\begin{array}{l}\text { Zarifian } \\
(2001, \text { p. 66) }\end{array}$ & $\begin{array}{l}\text { A competência profissional é uma combinação de } \\
\text { conhecimentos, de saber-fazer, de experiências e } \\
\text { comportamentos que se exercem em contexto preciso. Ela é } \\
\text { constatada na sua utilização em situação profissional a partir da } \\
\text { qual é passível de avaliação. Compete então à empresa } \\
\text { identificá-la, avaliá-la e fazê-la evoluir. }\end{array}$ & $\begin{array}{l}\text { Aptidão, ação e } \\
\text { resultado. }\end{array}$ \\
\hline
\end{tabular}

Fonte: Adaptado de BITENCOURT, C. C. Gestão de competências e aprendizagem nas organizações. São Leopoldo: Unisinos, 2005. p. 21-23.

No campo da educação, Perrenoud (1999) definiu competência como uma capacidade de agir eficazmente em um determinado tipo de situação, apoiada em conhecimentos, mas sem limitar-se a eles, ou seja, é a faculdade de mobilizar um conjunto de recursos cognitivos (saberes, capacidades e informações) para solucionar com pertinência e eficácia uma série de situações. Defende que as competências não são ensinadas, mas construídas por meio de uma prática reflexiva, pois são consideras um processo e não um estado. Assim, a competência humana é associada a desempenho e eficiência, os quais se encontram atrelados aos domínios do conhecimento na área da educação e à qualificação para o trabalho (FEUERSCHÜTTE; GODÓI, 2007).

Zarifian (2001, p. 66), cuja reflexão embasa-se nas relações de trabalho, 
destacou o conceito de competências como:

Uma combinação de conhecimentos, de saber fazer, de experiências e comportamentos que se exerce em um contexto preciso. Ela é constatada quando de sua utilização em situação profissional, a partir da qual é passível de validação. Compete então à empresa identificá-la, avaliá-la e fazê-la evoluir.

A competência é de um indivíduo e só se manifesta na sua utilização em situação prática, transformando os conhecimentos adquiridos em resultados. Assim, ele propõe uma nova definição do conceito de competências: "o tomar iniciativa e o assumir responsabilidade do indivíduo diante de situações profissionais com as quais se depara" (ZARIFIAN, 2001, p. 68). Tomar iniciativa ele compreende como começar alguma coisa nova no mundo. Enquanto que, assumir responsabilidade está relacionado à ideia de assumir em pessoa a responsabilidade pela avaliação da situação e pela iniciativa. Já situações profissionais, comportam um conjunto de elementos objetivos, dados da situação, implicações da tomada de responsabilidade e a maneira subjetiva que o indivíduo tem de interpretar a situação.

A competência também é tida como "um entendimento prático de situações que se apóia em conhecimentos adquiridos e os transforma na medida em que aumenta a diversidade das situações" (ZARIFIAN, 2001, p. 72). Com essa definição, o autor enfatiza a dinâmica da aprendizagem como essencial no procedimento da competência.

Seguindo a mesma linha conceitual, o francês Le Boterf (2003) afirma que a competência é o resultado do cruzamento de três eixos: o sujeito, envolvendo sua biografia e sua socialização; sua experiência profissional e a situação de sua formação educacional. Assim, a competência é um saber agir responsável e que é reconhecido pelos outros (LE BOTERF, 2003), portanto, a competência não pode ser copiada com exatidão, afinal, cada um desenvolve sua própria competência, por meio de treinamento, prática, erros, reflexão e repetição (SVEIBY, 1998).

Sveiby (1998) considerou que a competência de um indivíduo consiste em cinco elementos mutuamente dependentes: a) conhecimento explícito (fatos); b) habilidade (saber fazer); c) experiência (reflexão sobre erros e sucessos passados); d) julgamentos de valor (percepções) e, e) rede social.

Para autores como Swieringa e Wierdsma (1992), Zarifian (2001) e Ruas (2005), os conhecimentos, as habilidades e as atitudes que constituem as 
competências são recursos de competências, pois são essenciais para o desenvolvimento delas e se desdobram em: a) saber (conhecimentos) do ambiente, gerais, teóricos e operacionais; b) saber fazer (sabilidades), experiência profissional associada; c) saber ser/agir (atitudes), atributo profissional e atributos pessoais. Le Boterf (2003) agregou um quarto desdobramento: o saber aprender, que consiste em saber tirar lições de experiências.

Zarifian (2001) diferencia as competências de uma organização em: a) técnicas: conhecimentos específicos sobre o trabalho; b) sobre os processos de trabalho; c) sobre a organização: saber organizar os fluxos de trabalho; d) de serviço e e) sociais: autonomia, responsabilização e comunicação. Para Fleury e Fleury (2004), as competências técnicas consistem em deter informações e conhecimentos técnicos da área de atuação, ou seja, é o saber fazer, enquanto que as competências sociais ou psicológicas correspondem ao saber ser, incluindo atitudes que sustentam os comportamentos das pessoas.

Desta forma, competências individuais podem ser entendidas como um processo dinâmico que considera as capacidades do indivíduo, formadas por conhecimentos, habilidades e atitudes para a ação em uma dada situação complexa (ZARIFIAN, 2001; LE BOTERF, 2003) e está associada ao processo de aprendizagem (FEUERSCHÜTTE; ALPERSTEDT, 2008). Consiste em "saber agir responsável e reconhecido, que implica mobilizar, integrar, transferir conhecimentos, recursos, habilidades, que agreguem valor econômico à organização e valor social ao indivíduo" (FLEURY; FLEURY, 2004, p. 30).

Fernandes e Comini (2008) sugerem que as competências são um conjunto de conhecimentos, habilidades, atitudes e valores que um indivíduo mobiliza em um contexto, sujeito a mudanças e restrições, de forma a gerar valor econômico ao negócio e valor social a si próprio. Para Dutra (2004), o conceito de competências possui duas vertentes: as capacidades ou inputs, que consistem nos conhecimentos, habilidades, atitudes e valores (CHAV), como um estoque do indivíduo, e sua efetiva entrega à organização de forma a agregar valor. Por conhecimentos entendem-se dados e informações armazenadas no intelecto e resgatadas para interpretação dos fatos; habilidades significam destreza ou proficiência para realizar determinadas operações; atitudes consistem em constatações avaliativas ou predisposição em relação a algo; e valores consistem em concepções racionalizadas que influenciam 
escolhas de meios e fins. Note-se que cada uma destas capacidades isoladamente consideradas -ou mesmo combinadas- não garante uma competência, dado que o distintivo desta é sua aplicação. Assim, nesta mesma medida, o conceito de competência não se confunde com conhecimentos, habilidades, atitudes e valores; pelo contrário, absorve-os e canaliza-os para uma entrega que agrega valor.

Por fim, Dutra (2004) ainda destaca que uma noção constitutiva do conceito de competências é a noção de complexidade. Segundo o autor, a complexidade refere-se ao nível de abstração em que um profissional realiza seu trabalho, envolvendo a abrangência de tempo entre a tomada de decisão e as conseqüências desta ação no futuro (time spam), o impacto da decisão na organização (operacional, tático ou estratégico), o número de variáveis implicadas na decisão (um processo, uma unidade de negócios, toda a corporação), o escopo regional (local, nacional, internacional), entre outros. Nesta ótica, a competência é tanto mais pronunciada quanto mais é articulada e mobilizada em contextos mais complexos.

\subsection{COMPETÊNCIAS EMPREENDEDORAS}

Quando transposta ao campo do empreendedorismo, principalmente sob a forma de competências empreendedoras, observa-se que 0 conceito de competências assume novas conotações. Segundo Mamede e Moreira (2005, p. 4), "a competência empreendedora pode ser tratada tanto como competência do indivíduo quanto relacionada à prática administrativa, devido às diferentes tarefas que desempenham". Para eles, as ações empreendedoras estão associadas às competências por representarem o senso de identificação de oportunidades, a capacidade de relacionamento em rede, as habilidades conceituais, a capacidade de gestão, a facilidade de leitura, ao posicionamento em cenários conjunturais e ao comprometimento com interesses individuais e da organização.

Essa junção de competências com ações empreendedoras levaram à criação do conceito de competência empreendedora definido por Snell e Lau (1994), a qual consiste em corpo de conhecimento, área ou habilidade, qualidades pessoais ou características, atitudes ou visões, motivações ou direcionamentos, que pode, de diferentes formas, contribuir para o pensamento ou ação efetiva do negócio. Para os autores, a arte de criar e gerenciar um pequeno negócio está relacionada ao plano de vida do empreendedor, aos valores e à sua característica pessoal, e isto é 
refletido na amplitude dessa definição.

De acordo com Man e Lau (2000), a competência empreendedora pode ser considerada como tipo de característica superior que destaca os indivíduos denominados competentes por diferentes traços de personalidade, habilidades e conhecimentos, que se refletem na atitude. Esses traços são influenciados pela experiência de cada um, a sua educação tradicional e familiar (LE BOTERF, 2003). Para eles, o processo de competitividade das pequenas e médias empresas é fortemente influenciado pelo papel dos elementos chaves, ou seja, os empreendedores.

Antonello (2005) definiu competência empreendedora como um conjunto de conhecimentos, habilidades e atitudes que viabilizam a um indivíduo imprimir sua visão, estratégias e ações na criação de valor (tangíveis ou intangíveis) para a sociedade. A autora argumenta ainda que as competências necessárias ao completo desempenho do papel empreendedor mudam com o contexto de cada negócio, portanto, o empreendedor deve desenvolver mais uma competência denominada de capacidade de leitura de contextos.

Baron e Shane (2007) apresentam cinco competências sociais que podem ser úteis aos empreendedores: a) percepção social (habilidade de interpretar os outros corretamente); b) expressividade (habilidade de expressar suas próprias reações e emoções de forma que elas possam ser percebidas pelos outros, contagiando-os); c) administração da imagem (habilidade em causar uma primeira boa impressão); d) persuasão e influência (habilidade para mudar atitudes ou comportamentos dos outros); e) adaptabilidade social (habilidade em adaptar-se a várias situações e sentir-se confortável.

A literatura mostra que os estudos sobre competências empreendedoras são recentes, tendo sido predominantes apenas nos últimos 10 anos. Alguns estudos procuraram compreender este conceito no contexto empreendedor. As pesquisas nacionais encontradas estão brevemente relatadas a seguir.

O estudo de Leiria (2002) teve como objetivo identificar quais competências os empreendedores colocam em ação para desenvolver em suas organizações os fatores que determinam o sucesso dos seus negócios. A pesquisa foi realizada através de entrevista semi-estruturada, com 12 empreendedores dos setores da indústria, comércio e serviços na Região Metropolitana de Porto Alegre, no Rio 
Grande do Sul. Todas as empresas foram vencedoras do Prêmio Talentos Empreendedores nos anos de 1998 a 2001. A autora observou que no universo das pequenas empresas as competências que determinam a sobrevivência da organização estão centradas na pessoa do empreendedor, que é quem determina a estratégia do negócio. Identificou também que as competências mais utilizadas e que garantem a sobrevivência dos empreendimentos estão concentradas em: preocupação com tecnologias voltadas para inovação, atenção para oportunidade de novos mercados, início do processo de exportação, maior atenção com a conquista de novos clientes e a manutenção e fidelização dos já existentes.

Paiva Jr., Fernandes e Almeida (2006) analisaram quais dimensões da competência de relacionamento auxiliam no fortalecimento dos laços de cooperação de duas empresas de base tecnológica do pólo de tecnologia da informação da Região Metropolitana do Recife, tendo em vista que a competência de relacionamento pode contribuir para ativar a rede social do empreendedor e auxiliálo a fortalecer sua atividade empresarial, pois a rede de relacionamentos dá forma ao capital social e possibilita ao empreendedor encontrar recursos que possibilitem a expansão e institucionalização de seu empreendimento. Os autores verificaram que a sustentabilidade do empreendedor nas redes é perpassada pelo desenvolvimento de alianças, obtidas por meio de integridade na interação social. A competência relacional utilizada para construir relações de confiança gera credibilidade que possibilita a expansão do negócio a partir da fidelidade, gerando relações duradouras. Para que haja os relacionamentos de cooperação é preciso que haja relações de confiança, acordos sobre os movimentos, sentimento de pertencimento, equilíbrio de poderes, trocas de informações transparentes e compartilhamento de valores. Portanto, para que as parcerias sejam efetivas e duradouras é importante a escolha de parceiros com credibilidade, valores e objetivos comuns, assim como a sensibilidade interpessoal e o entendimento do outro são necessários.

Feuerschütte e Godoi (2007) estudaram a competência sob uma perspectiva dinâmica, ou seja, a competência expressa na ação. Elas objetivaram caracterizar as competências de empreendedores do setor hoteleiro, por meio da aproximação às suas experiências e atuação à frente do empreendimento. Para tal, elas realizaram entrevistas em profundidade com cinco empreendedores do ramo de hotelaria do Estado de Santa Catarina. Identificaram três grupos de competências: 
a) competências relativas às características pessoais do empreendedor, tais como: recursos emocionais, aptidões ou qualidades, desejos e expectativas, aprimoramento contínuo e a história da família; b) competências relativas à gestão do empreendimento: uso das experiências na gestão; associação de conhecimentos e experiências anteriores; prática do acompanhamento, da intervenção e da avaliação sistemática; c) competências relacionadas ao empreendimento e seu contexto: capacidade do empreendedor de identificar no ambiente as possibilidades de negócio e de buscar informações e saber analisar tendências (oportunidade), e articulação e formação de redes para resolver problemas comuns, administrar conflitos, negociar sobre bases de confiança e uso da verdade (relacionamento). De acordo com as autoras (2007, p. 13) "a associação entre conhecimentos e experiências, com a produção de novos saberes aplicados a novos contextos, mostra que a competência em ação alavanca o processo de aprendizagem".

Pardini, Brandão e Souki (2008) analisaram a influência das competências empreendedoras e das redes de relações sociais do fisioterapeuta na escolha do negócio ou atividade a ser desenvolvido na área, por meio de entrevistas com 23 fisioterapeutas na Região Metropolitana de Belo Horizonte. Constatou-se que, inicialmente, as competências são desenvolvidas no ambiente acadêmico e organizacional, no entanto, as competências associadas à visão do ambiente são obtidas por meio da experiência profissional. Percebeu-se ainda que a ação intuitiva ocorre no processo de escolha da atividade a ser empreendida e após a abertura do negócio. Assim como as competências associadas à ação estratégica dizem respeito a se antecipar ao mercado e oferecer serviços pioneiros e diferenciados. Quanto aos relacionamentos, observou-se que as principais redes são familiares, acadêmicas, outros profissionais da área de saúde e com os pacientes.

Cabral (2008) pesquisou o Arranjo Produtivo Local (APL) de confecções do Agreste Pernambucano, com três municípios produtores de destaque: Santa Cruz do Capibaribe, Toritama e Caruaru, para verificar que competências foram desenvolvidas por empreendedores da APL para que alcançassem a condição de liderança. Para tal, foram realizadas entrevistas com 21 proprietários líderes e 14 com outros atores, como dirigentes de sindicatos e consultores do SEBRAE e SENAI. O autor descobriu que os empreendedores para aumentar suas competências, além do modo tácito, têm investido em aprendizagem formal. Já as 
competências transacionais foram adquiridas através das relações com mercados diferenciados de fornecedores e clientes. A expansão das empresas tem sido fruto de competências alocativas pela capacidade de conquista evolutiva de novos mercados, aliada com a competência técnica proveniente da adoção de estratégias tecnológicas mistas.

Barini Filho (2008) em seu estudo cujo objetivo era obter dados empíricos sobre os processos educacionais no contexto das organizações empresariais que possibilitam a formação de empreendedores internos, realizou um estudo de múltiplos casos com cinco empresas familiares de capital nacional, em fase de sucessão ou de profissionalização, fundadas há pelo menos 20 anos, das quais foram entrevistados 27 gestores entre fundadores, presidentes, sucessores e gerentes de primeiro escalão, responsáveis pela manutenção da cultura empresarial das empresas participantes. Para tal o autor utilizou de entrevista semi-estruturada, questionários e grupo focal. Um dos questionários elaborado pelo autor baseou-se na teoria da cognição social de Bandura (1986) e abordava a formação da competência empreendedora. O outro questionário foi construído com base em Carrier (1996) e Pinchot III (1989) e pretendia avaliar se os respondentes valorizam ou praticam os princípios do empreendedorismo em seu dia-a-dia. Já o terceiro questionário, o objetivo era aferir o entendimento do empreendedorismo corporativo, identificando se a empresa oferece espaço para o empreendedorismo corporativo e a inovação, à luz da teoria de Carrier (1996) e Dolabela (1999). A análise consolidada das cinco organizações pesquisadas aponta claramente para um ambiente predominantemente empreendedor em três das cinco, segundo a avaliação dos entrevistados. Independente dos estágios de cada sucessão ficou visível a movimentação interna para aquisição coletiva de novas competências. As empresas pesquisadas neste trabalho estavam envolvidas com inovação de alguma maneira e são exemplos da busca da competição em novos contextos. De acordo com Barini Filho (2008), as evidências qualitativas das empresas familiares pesquisadas por ele permitem afirmar que existe um processo educacional que suporta a formação de empreendedores.

Dentro do tema de competências empreendedoras, alguns autores tem se preocupado em criar tipologias ou modelos que possibilitam a identificação por parte dos pesquisadores, dos conhecimentos, habilidades e atitudes, enfim, das 
competências necessárias ao desenvolvimento de suas atividades. Dentre eles, dois trabalhos foram identificados na literatura: o de Cooley (1990) e o de Man e Lau (2000).

\subsection{TIPOLOGIAS DE COMPETÊNCIAS EMPREENDEDORAS}

A classificação de Cooley (1990) é voltada especificamente para os empreendedores e foi revisada e adaptada do modelo de competências de McClelland, onde existem comportamentos e características empreendedoras, que podem diferenciar empreendedores bem sucedidos de outros. Essa classificação é utilizada hoje pelo Programa das Nações Unidas para o Desenvolvimento (PNUD) e também pelo SEBRAE, no Brasil, para programas de capacitação dos empreendedores, como o Programa para Empresários e Futuros Empreendedores EMPRETEC (HONMA, 2007).

A tipologia de Cooley (1990) contém uma lista com 10 competências empreendedoras, as quais estão descritas no Quadro 3. O quadro foi construído com base em 10 categorias analíticas, as quais correspondem a determinados elementos de análise. As categorias envolvem temas como oportunidade, gestão, rede de contatos, qualidade e eficiência e outras características pessoais como persistência, comprometimento, correr riscos, independência e auto-confiança. 
Quadro 3 - Competências empreendedoras

\begin{tabular}{|c|c|}
\hline Categorias Analíticas & Elementos de Análise \\
\hline \multirow{2}{*}{$\begin{array}{l}\text { Busca de } \\
\text { oportunidade e } \\
\text { iniciativa }\end{array}$} & $\begin{array}{l}\text { Aproveitar oportunidades fora do comum para começar novo negócio, obter } \\
\text { financiamento, equipamentos terrenos, local de trabalho ou assistência. }\end{array}$ \\
\hline & $\begin{array}{l}\text { Fazer as coisas antes de solicitado, ou antes, de forçado pelas } \\
\text { circunstâncias. }\end{array}$ \\
\hline \multirow{3}{*}{ Persistência } & Agir diante de um obstáculo significativo. \\
\hline & $\begin{array}{l}\text { Agir repetidamente ou mudar para uma estratégia alternativa, a fim de } \\
\text { enfrentar desafios ou superar obstáculos. }\end{array}$ \\
\hline & $\begin{array}{l}\text { Fazer sacrifícios pessoais ou despender esforços extraordinários para } \\
\text { completar tarefas. }\end{array}$ \\
\hline \multirow{3}{*}{ Comprometimento } & $\begin{array}{l}\text { Juntar-se aos empregados ou colocar-se no lugar deles, se necessário, } \\
\text { para terminar trabalhos. }\end{array}$ \\
\hline & $\begin{array}{l}\begin{array}{l}\text { Assumir responsabilidade pessoal pelo desempenho que visa ao } \\
\text { consecução de metas e objetivos. }\end{array} \\
\end{array}$ \\
\hline & $\begin{array}{l}\text { Esmerar-se em manter os clientes satisfeitos e colocar em primeiro lugar a } \\
\text { boa vontade de longo prazo, acima do lucro de curto prazo. }\end{array}$ \\
\hline \multirow{3}{*}{$\begin{array}{l}\text { Exigência de } \\
\text { qualidade e Eficiência }\end{array}$} & $\begin{array}{l}\text { Agir de maneira a fazer as coisas que satisfazem ou excedem padrões de } \\
\text { excelência. }\end{array}$ \\
\hline & $\begin{array}{l}\text { Encontrar maneiras de fazer as coisas de forma melhor, mais rápida e/ou } \\
\text { barata. }\end{array}$ \\
\hline & $\begin{array}{l}\text { Desenvolver ou utilizar procedimentos para assegurar que o trabalho seja } \\
\text { terminado a tempo ou que o trabalho atenda a padrões de qualidade } \\
\text { previamente combinados. }\end{array}$ \\
\hline \multirow{3}{*}{$\begin{array}{l}\text { Correr riscos } \\
\text { calculados }\end{array}$} & Avaliar alternativas e calcular riscos deliberadamente. \\
\hline & Agir \\
\hline & Colo \\
\hline \multirow{3}{*}{$\begin{array}{l}\text { Estabelecimento de } \\
\text { metas }\end{array}$} & $\begin{array}{l}\text { Estabelecer metas e objetivos que são desafiantes e que têm significado } \\
\text { pessoal. }\end{array}$ \\
\hline & Definir objetivos de longo prazo, claros e específicos. \\
\hline & Est \\
\hline \multirow{2}{*}{ Busca de informações } & $\begin{array}{l}\text { Dedicar-se pessoalmente a obter informações de clientes, fornecedores e } \\
\text { concorrentes. }\end{array}$ \\
\hline & Investigar pessoalmente como fabricar produto ou como fornecer serviço. \\
\hline \multirow{4}{*}{$\begin{array}{l}\text { Planejamento e } \\
\text { monitoramento } \\
\text { sistemáticos }\end{array}$} & ar dividindo tarefas de arande porte em s \\
\hline & definidos. \\
\hline & 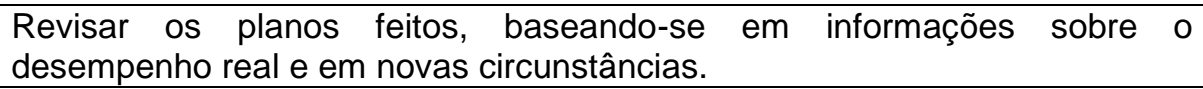 \\
\hline & Manter registros financeiros e utilizá-los para tomar decisões. \\
\hline \multirow{3}{*}{$\begin{array}{l}\text { Persuasão e rede de } \\
\text { contatos }\end{array}$} & Utilizar estratégias deliberadas para influenciar ou persuadir os outros. \\
\hline & $\begin{array}{l}\text { Utilizar pessoas chaves como agentes de consecução dos seus próprios } \\
\text { objetivos. }\end{array}$ \\
\hline & Agir para desenvolver e manter relações comerciais. \\
\hline \multirow{3}{*}{$\begin{array}{l}\text { Independência e } \\
\text { Autoconfiança }\end{array}$} & Buscar autonomia em relação a normas e controles de outros. \\
\hline & $\begin{array}{l}\text { Manter seu ponto de vista, mesmo diante da oposição ou de resultados } \\
\text { desanimadores. }\end{array}$ \\
\hline & $\begin{array}{l}\text { Expressar confiança na sua própria capacidade de completar tarefas difíceis } \\
\text { ou de enfrentar desafios. }\end{array}$ \\
\hline
\end{tabular}

Fonte: COOLEY, L. Entrepreneurship Training and the strengthening of entrepreneurial performance. Final Report. Washington: USAID, 1990.

Morales (2004) utilizou esta tipologia para fazer um estudo sobre competências, buscando medir o grau de relação entre as competências empreendedoras e os tipos psicológicos junguianos. A pesquisa envolveu 82 
empreendedores, no Estado de Santa Catarina e foi realizada por meio de entrevista focada, baseando-se em uma lista de 10 características comportamentais de empreendedores e 30 definições operacionais, com uma correlação com os tipos psicológicos de Jung. As características comportamentais empreendedoras predominantes na amostra de Santa Catarina foram: a) busca de informações, b) persuasão e redes de contato e, c) persistência. Observou-se baixa correlação entre as características empreendedoras e os traços psicológicos. "Quanto ao perfil dos empreendedores brasileiros no tocante ao modelo de competências proposto por Cooley, há poucos estudos sobre este assunto, o que dificulta uma comparação entre o perfil dos diferentes estados ou regiões" (MORALES, 2004, p. 163).

Para Man e Lau (2000), a competitividade na MPE - enquanto conceito multidimensional que envolve desempenho e o processo de desenvolver 0 desempenho -, é fortemente influenciada pelas competências do empreendedor. Partindo deste pressuposto, os autores realizaram diversos estudos empíricos entre 1993 e 1999 que resultaram em uma categorização de competências em seis áreas distintas. O Quadro 4 ilustra essa tipologia.

Quadro 4 - Áreas de competências e seus focos comportamentais

\begin{tabular}{|l|l|}
\hline \multicolumn{1}{|c|}{$\begin{array}{c}\text { Áreas de } \\
\text { Competências }\end{array}$} & \multicolumn{1}{|c|}{ Foco Comportamental } \\
\hline $\begin{array}{l}\text { Competências de } \\
\text { Oportunidades }\end{array}$ & $\begin{array}{l}\text { Competências relacionadas ao reconhecimento de oportunidades de } \\
\text { mercados em suas diferentes formas. }\end{array}$ \\
\hline $\begin{array}{l}\text { Competências de } \\
\text { Relacionamento }\end{array}$ & $\begin{array}{l}\text { Competências relacionadas às interações baseadas nos relacionamentos } \\
\text { entre indivíduos e indivíduos e grupos. }\end{array}$ \\
\hline $\begin{array}{l}\text { Competências } \\
\text { Conceituais }\end{array}$ & $\begin{array}{l}\text { Competências relacionadas às diferentes habilidades conceituais que estão } \\
\text { refletidas no comportamento do empreendedor. }\end{array}$ \\
\hline $\begin{array}{l}\text { Competências } \\
\text { Administrativas }\end{array}$ & $\begin{array}{l}\text { Competências relacionadas com a organização de diferentes recursos } \\
\text { internos e externos, recursos humanos, físicos, financeiros e tecnológicos. }\end{array}$ \\
\hline Competências & $\begin{array}{l}\text { Competências relacionadas à escolha, avaliação e implementação das } \\
\text { Estratégicas }\end{array}$ \\
\hline estratégias da empresa. \\
Competências de & $\begin{array}{l}\text { Competências que demandam habilidade de manter a dedicação do dirigente } \\
\text { Comprometimento negócio. }\end{array}$ \\
\hline
\end{tabular}

Fonte: MAN, T. W. Y.; LAU, T. Entrepreneurial competencies of SME owner/managers in the Hong Kong services sector: a qualitative analysis. Journal of Enterprising Culture, v. 8, n. 3. Sept. 2000, p. 237.

As competências para Man e Lau (2000) são demonstradas por comportamentos observáveis condicionantes da capacidade pessoal de realizar ações estratégicas de expansão empresarial. Assim, os autores caracterizaram as competências empreendedoras em seis áreas distintas de comportamentos, conforme se constata resumidamente no Quadro 5 e melhor explicitadas na seqüência. 
Quadro 5 - Competências empreendedoras

\begin{tabular}{|c|c|}
\hline Clusters & Componentes Comportamentais \\
\hline \multirow{3}{*}{ Oportunidade } & Identificar = oportunidades de negócios e lacunas de mercado. \\
\hline & Avaliar = mercados não atendidos, tendências e mudanças do mercado. \\
\hline & Buscar = pesquisar oportunidades através de pesquisa de mercado/marketing. \\
\hline \multirow{7}{*}{ Relacionamento } & Construir e manter redes de relacionamentos. \\
\hline & Utilizar-se das redes de relacionamentos. \\
\hline & Expor suas habilidades para a mídia para construir imagem. \\
\hline & Comunicar = efetivamente e eficientemente. \\
\hline & Negociar = com sócios ou parceiros. \\
\hline & Administrar conflitos = evitar e resolver os conflitos. \\
\hline & Construir consenso com os parceiros de negócios. \\
\hline \multirow{4}{*}{ Conceituais } & Pensar intuitivamente. \\
\hline & Ver por ângulos diferentes = observar, analisar e avaliar de forma subjetiva. \\
\hline & Inovar = diferenciar-se em mercados, produtos e tecnologias. \\
\hline & Avaliar riscos. \\
\hline \multirow{6}{*}{ Administrativas } & Planejar as operações e utilização de recursos. \\
\hline & Adquirir e usar recursos de forma eficiente. \\
\hline & Liderar empregados. \\
\hline & Motivar empregados para atingirem as metas. \\
\hline & Delegar responsabilidades para profissionais capacitados. \\
\hline & Controlar. \\
\hline \multirow{9}{*}{ Estratégicas } & Ter visão abrangente e de longo prazo. \\
\hline & Estabelecer e avaliar metas. \\
\hline & Fazer uso dos recursos e capacidades da empresa. \\
\hline & Realizar mudanças estratégicas. \\
\hline & Definir e avaliar posicionamento em um nicho de mercado. \\
\hline & Executar as metas estabelecidas. \\
\hline & Usar táticas frente aos clientes e competidores. \\
\hline & Estimar a viabilidade financeira da implementação da estratégia. \\
\hline & Monitorar os resultados da implementação das estratégias. \\
\hline \multirow{7}{*}{ Comprometimento } & Manter o compromisso com o negócio. \\
\hline & Comprometer-se com metas de longo prazo. \\
\hline & Dedicar-se ao trabalho. \\
\hline & Ser responsável pela atuação dos empregados. \\
\hline & Comprometer-se com crenças e valores. \\
\hline & Comprometer-se com os próprios interesses. \\
\hline & Disposição para reiniciar a atividade mesmo após si \\
\hline
\end{tabular}

Fonte: MAN, T. W. Y.; LAU, T. Entrepreneurial competencies of SME owner/managers in the Hong Kong services sector: a qualitative analysis. Journal of Enterprising Culture, v. 8, n. 3. Sept. 2000, p. 240

Esta categorização incorpora, de certa forma, os elementos de análise citados por Cooley (1990) nas categorias de competências empreendedoras, avançando na apresentação de clusters de comportamento para cada categoria.

- Competências de Oportunidade estão relacionadas à identificação, avaliação e busca de oportunidades de negócios. De acordo com Paiva Jr., Leão e Mello (2003, p. 2) "um empreendedor deve estar apto a identificar os cenários favoráveis aos objetivos organizacionais e atuar sobre as potenciais chances de negócios por meio da sua avaliação de modo a transformá-las em situações positivas". Essa capacidade de visualizar o ambiente que antecede e ampara o 
processo de decisão é fundamental para os empreendedores que, segundo Filion (1999), tem visões cuja elaboração demanda tempo, comprometimento e imaginação sobre o objetivo a ser perseguido e os caminhos necessários para realizá-lo. O empreendedor também está voltado para a definição de contexto e a organização dos recursos necessários para fazer frente às oportunidades e ameaças ambientais. Filion (1991) classificou a visão empreendedora em três categorias: emergente (desenvolvimento de produtos e serviços que apresentam potencial de mercado), central (decorrente de uma ou mais visões emergentes, podendo ser originada de uma visão externa e/ou interna, que indicam os caminhos para viabilizar o negócio) e a complementar que está associada às atividades gerenciais necessárias para dar suporte à visão central. Para a concretização de uma visão empreendedora, criatividade, motivação e inovação são essenciais (BERGAMINI, 1997; BERNARDI, 2003).

- Competências de Relacionamento referem-se aos relacionamentos pessoais do empreendedor (GRANOVETTER, 1985), os quais estão classificados em três níveis por Filion (1991): primários (abrangem os contatos familiares e as pessoas mais próximas), secundários (amizades e grupos sociais: clubes, religião, política, trabalho, etc.) e terciários (contatos com um campo de interesse e ocorrem através de viagens, cursos, exposições, feiras e congressos). Esses relacionamentos podem influenciar na definição do caminho a ser seguido em um determinado negócio. Já durante a realização das atividades, esta competência envolve comunicação adequada, relacionamento eficiente e capacidade de negociação, quer seja com os funcionários, quer seja com clientes, fornecedores, sócios ou governo, além da capacidade de resolver conflitos do dia-a-dia.

- Competências Conceituais dizem respeito às capacidades de avaliar situações de risco que surgem em decorrência de suas ações em qualquer ambiente, ou seja, o empreendedor tende a correr riscos calculados (DORNELAS, 2007); e também à capacidade de perceber situações por ângulos diferentes e forma positiva, como por exemplo: quando a maioria das pessoas vê o mercado saturado, os empreendedores são capazes de descobrir nichos para penetrar nesse mercado e se adaptar a novas situações, não somente relacionado a novos produtos e tecnologias, mas também à reformulação dos produtos e serviços já existentes ou ainda, à penetração em outros mercados (MAN; LAU, 2000). Assim, a inovação 
permite a diferenciação e integra a dimensão conceitual da competência empreendedora.

- Competências Administrativas envolvem a eficiente alocação de talentos humanos, recursos físicos, financeiros e tecnológicos. Para tal é preciso ter a capacidade de planejar, organizar, comandar, motivar, delegar e controlar, enfim, administrar o empreendimento e seus funcionários (MAN; LAU, 2000).

- Competências Estratégicas vinculam-se à escolha e implementação das estratégias do empreendimento, onde os empreendedores visualizam panoramas de longo prazo e objetivos de médio e curto prazos alcançáveis e realistas, além de elaborar estimativas de viabilidade financeira de mecanismos de controle dos seus resultados (MAN; LAU, 2000). Para Mintzberg, Ahlstrand e Lampel (2000), os empreendedores devem estar aptos para perceber tendências emergentes no ambiente, sintonizar-se com informações diversas e conseguir ajustar suas percepções na direção das forças ambientais. Já Kets de Vries (1997) afirmam que esses indivíduos devem ser mais hábeis que os demais membros da organização para gerenciar toda essa complexidade.

- Competências de Comprometimento são as que demandam a habilidade de manter a dedicação do dirigente ao negócio, principalmente em situações adversas, além de demonstrar a dedicação do empreendedor e de seu trabalho árduo, participando de tudo o que acontece na organização, mesmo que em detrimento de sua vida pessoal. Man e Lau (2000) também mencionam que essa competência está relacionada ainda com a capacidade que o empreendedor tem de recomeçar a atividade empresarial, mesmo após situações de insucesso, ou então, a disposição de não abandonar o negócio mesmo quando ocorrem crises setoriais ou na economia. Paiva Jr., Leão e Mello (2003, p. 4) comentam que "muitas vezes a dedicação à atividade empresarial vincula-se a outras motivações, tais como o senso de responsabilidade com respeito à equipe ou mesmo à manutenção de crenças e valores pessoais". Cooley (1990) refere-se a esta competência como persistência, o que envolve: agir diante de um obstáculo significativo e fazer sacrifícios pessoais ou despender esforços extraordinários para completar tarefas. Além da persistência, o autor também cita a independência e autoconfiança no sentido de expressar confiança na sua própria capacidade de completar tarefas difíceis ou de enfrentar desafios e no sentido de manter seu ponto de vista, mesmo 
diante da oposição ou de resultados desanimadores.

A partir da tipologia citada, Man e Lau (2000) incorporaram as seis áreas de competências em diferentes dimensões de competitividade e as relacionaram a três tarefas empreendedoras, como pode ser visto no Quadro 6.

Quadro 6 - Tarefas empreendedoras e as áreas de competências requeridas

\begin{tabular}{|c|c|}
\hline Tarefas Empreendedoras & Áreas de Competências Relacionadas \\
\hline \multirow{3}{*}{ 1. Formando o escopo competitivo da empresa. } & Competências de oportunidades \\
\hline & Competências de relacionamento \\
\hline & Competências conceituais \\
\hline \multirow{3}{*}{ 2. Criando capacidades organizacionais. } & Competências administrativas \\
\hline & Competências de relacionamento \\
\hline & Competências conceituais \\
\hline \multirow{2}{*}{$\begin{array}{l}\text { 3. Definindo metas e tomando decisões em } \\
\text { direção às metas, avaliando o escopo e usando } \\
\text { as capacidades organizacionais. }\end{array}$} & Competências estratégicas \\
\hline & Competências de comprometimento \\
\hline
\end{tabular}

Fonte: MAN, T. W. Y.; LAU, T. Entrepreneurial competencies of SME owner/managers in the Hong Kong services sector: a qualitative analysis. Journal of Enterprising Culture, v. 8, n. 3. Sept. 2000, p. 239

De acordo com essa estrutura, existem três grandes tarefas empreendedoras, ligando diferentes construtos. Primeiro, tem-se a tarefa da formação do escopo competitivo como um construto subjetivo que é percebido pelo empreendedor. Esta tarefa é afetada pelas habilidades do empreendedor em interpretar as condições ambientais por meio da competência de oportunidade para criar contatos e conexões para as oportunidades de negócios, da competência de relacionamento e de competências conceituais. A segunda tarefa de criação de capacidades organizacionais requer competências administrativas e de relacionamento, para integrar os recursos organizacionais internos e externos, e competências conceituais na solução e análise dos problemas organizacionais. A última tarefa, de metas e decisões, envolve a competência estratégica que é a principal competência requerida na tarefa de definição dos rumos da empresa, e de comprometimento para sustentar e melhorar o desempenho do empreendimento, em longo período de tempo.

Várias pesquisas foram realizadas utilizando especificamente a tipologia de competências empreendedoras de Man e Lau (2000). Paiva Jr., Leão e Mello (2003), realizaram um estudo cujo desafio consistiu em apresentar os resultados de áreas de competências empreendedoras de dirigentes de empresas que atuam na nova economia, os quais demonstram que o estoque de competências específicas acumuladas pelos dirigentes estão no saber fazer e o saber ser peculiares à prática empreendedora. Para tal, foi realizada uma pesquisa qualitativa com sete entrevistas 
semi-estruturadas e em profundidade com dirigentes de empresas brasileiras de médio e grande porte que atuam em serviços da nova economia, sediadas no eixo Rio-São Paulo. Todas as áreas de competências foram identificadas no estudo, prevalecendo as competências conceituais, administrativas, de comprometimento e estratégicas. Os autores descobriram uma nova competência intitulada de competência de equilíbrio trabalho/vida pessoal, a qual compreende o equilíbrio entre a dinâmica de trabalho e as demandas do cotidiano do dirigente. Essa competência envolve os comportamentos: a) aprender com experiências passadas, dos outros e dos livros; b) adaptar as experiências passadas, dos outros e dos livros; c) administrar seu próprio tempo corretamente; d) avaliar suas habilidades, sua carreira e seu papel na empresa; e) equilibrar o trabalho com a vida familiar, lazer e saúde; f) administrar as angústias e estresse e; g) possuir integridade.

Mamede e Moreira (2005) utilizaram o modelo de Man e Lau (2000) para compreender o perfil de competências empreendedoras entre portugueses e cearenses nos hotéis localizados em Fortaleza. Foram realizadas duas entrevistas semi-estruturadas com dois empreendedores, sendo um cearense e outro português. Constatou-se algumas diferenças e similaridades entre os dois empreendedores. Com relação à competência de oportunidade, foi observada nos dois empreendedores. Os dois empreendedores demonstraram vontade de aprender, capacidade de inovação e facilidade de assumir riscos em meio aos cenários obscuros e de incerteza do mercado turístico, assim como, ambos dedicam-se inteiramente às atividades profissionais. Percebeu-se que as competências estratégicas são um traço marcante no perfil do empreendedor português e também debilidade nas características do perfil empreendedor cearense no que diz respeito ao planejamento de suas atividades e a dificuldade no relacionamento com seus funcionários.

Fonseca et al. (2006) pesquisaram 387 textos e entrevistas extraídas da internet no período de julho a agosto de 2004 acerca do empreendedor Miguel Abuhab, fundador de umas das maiores empresas de Tecnologia da Informação do Brasil, DATASUL, considerado duas vezes o melhor empreendedor do ano e amplamente reconhecido como um empreendedor de sucesso. As categorias de análise definidas pelos autores basearam-se nas áreas de competências de Man e Lau (2000), sendo que todas elas foram identificadas no empreendedor, 
destacando-se: a) oportunidade - identificar oportunidades a partir de experiências prévias, por meio de esforços de marketing e avaliar os espaços de mercado não atendidos; b) relacionamento - construir, manter e utilizar as redes de relacionamentos com os stakeholders; c) conceituais - raciocinar de forma criativa, inovar, lidar com o risco, ter vocação empreendedora para negócios, ter autonomia e aprender; d) gerenciais - planejar, organizar, liderar e atuar mercadologicamente; e) visão de mercado - conceber uma proposta de negócio, estabelecer e avaliar ações para concretização da proposta; f) comprometimento - com o negócio e com seus ideais; g) equilíbrio trabalho e vida pessoal - dar vazão ao estresse e ter uma compreensão prazerosa do trabalho.

Paiva Jr. et al. (2006) identificaram junto aos dirigentes de duas empresas graduadas pelo sistema de incubação que atuam na Região Metropolitana do Recife, através de entrevistas semi-estruturadas e em profundidade, a emergência de competências empreendedoras constitutivas das ações dos empreendedores, com base em Man e Lau (2000). Os autores constataram que a competência de relacionamento apresentou maior representatividade, reforçando a importância das incubadoras como ambiente catalisador das práticas de redes de negócios. Em seguida relataram as competências conceituais que envolvem as habilidades de observar as oportunidades do ambiente e de ser eficaz na alocação de talentos e de recursos financeiros, físicos e tecnológicos; além das habilidades de raciocinar criativamente, inovar e ter vontade de aprender. Na seqüência identificou-se as competências administrativas, envolvendo organização, liderança, planejamento e controle e as competências de reconhecimento de oportunidade associado à experiência vivenciada pelo empreendedor e estratégica, ligada ao planejamento e ao posicionamento do produto/negócio no mercado. Já, as competências de comprometimento e equilíbrio trabalho e vida pessoal foram as que tiveram os menores índices percentuais em relação ao número de citações.

Honma (2007) realizou um estudo de casos múltiplos, onde analisou as competências empreendedoras dos proprietários de seis hotéis de pequeno e médio porte em Curitiba/PR. Para tal, realizou entrevistas semi-estruturadas, com questões abertas e fechadas e usou o modelo adaptado de Man e Lau (2000) e Cooley (1990), considerando as competências de oportunidade, de comunicação, de comprometimento, de planejamento, de mobilização, de qualidade de vida e de 
interpretação. O autor relata que não é possível afirmar que os entrevistados apresentem, de maneira uniforme, todos os sete conjuntos de competências do estudo, em função da variação de perfis profissionais e pessoais, experiências, histórias de vida, ambientes em que estão inseridos, características dos empreendimentos, diferentes ciclos de vida das empresas, mercados, estratégias e posicionamentos, entre outros. Entretanto, percebeu a predominância de algumas competências específicas, dentro de cada conjunto de competências, que foram destacadas pelos empreendedores. Segundo os empreendedores de hotéis de pequeno porte, seriam os conjuntos de competências de comunicação, competências de mobilização e competências de qualidade de vida. Para os empreendedores de hotéis de médio porte, os conjuntos de competências mais relevantes a serem desenvolvidas seriam as de planejamento e as de qualidade de vida.

Dias, Nardelli e Vilas Boas (2008) identificaram as competências empreendedoras relacionadas aos cinco dos seis dirigentes empreendedores ganhadores do prêmio TOP Empresarial 2006, promovido pelo SEBRAE/RJ, nas áreas de comércio, educação, indústria, saúde, serviços, turismo e energia. Para tal basearam-se nas áreas de competências de Man e Lau (2000). Este estudo reforçou a existência das competências empreendedoras de Man e Lau (2000) nos empreendedores brasileiros e ressaltou a importância de algumas competências para alcançar o sucesso, tais como: ser inovador, pensar intuitivamente, assumir riscos calculados, criatividade, independência e autoconfiança, persistência, orgulho e auto-estima, perfeccionismo, educação formal e capacitação, além da ética.

\section{CONSIDERAÇÕES FINAIS}

O confronto da discussão sobre competências, sobretudo proveniente do campo de gestão de pessoas, com a apropriação que se faz deste conceito no campo de empreendedorismo, põe em evidência a frouxidão com que o tema vem sendo abordado.

Observe-se, por exemplo, a tipologia de Man e Lau (2000). O que os autores classificam como competências de comprometimento não é, a rigor, uma competência. Para os autores, tais competências caracterizam-se por comportamentos como "Manter o compromisso com o negócio; Comprometer-se 
com metas de longo prazo; Dedicar-se ao trabalho; Ser responsável pela atuação dos empregados; e comprometer-se com crenças e valores". Segundo reflexões recentes no campo de competências, tais características consistem em atitudes, ou predisposições em relação a algo. Da mesma forma, o modelo de Cooley (1990), além do comprometimento, enumera competências como persistência e independência e autoconfiança, que manifestam atitudes ou mesmo traços de personalidade. Ou Baron e Shane (2007), que sugerem ser competências habilidades ou atitudes como percepção social, expressividade, administração da imagem, persuasão e influência, e adaptabilidade social.

Como conseqüência, quaisquer aspectos comportamentais à luz destes trabalhos passam a ser denominados competências, o que de certo modo esvazia o conceito de competências e acarreta, indiretamente, perda de assertividade aos resultados dos trabalho neste tema realizados sob a ótica do empreendedorismo.

Como proposta de encaminhamento metodológico, uma opção é abandonar o termo competências para tais estudos, adotando nomenclaturas mais genéricas como comportamentos.

Outra opção, voltada à identificação mais assertiva de competências em sentido estrito, consistem em mapear comportamentos geradores de valor ou contribuições resultantes da ação empreendedora. Nesta ótica, seriam competências empreendedoras: identificar e explorar oportunidades, mobilizar pessoas e equipes em torno de um objetivo, implementar a adaptar estratégias, entre outros. Observe-se que, nesta perspectiva, o conceito de competência aproxima-se daquilo que Man e Lau (2000) chamam de tarefas empreendedoras.

Por fim, o conceito de competências vem sendo trabalhado de forma associada à noção de complexidade. Nos estudos sobre competências empreendedoras realizados até o momento, não se observa tal associação. Em termos práticos, não se deve observar se o empreendedor identifica ou não oportunidades, mas que tipo de oportunidades identifica. Por exemplo, suponhamse dois empreendedores: um primeiro identifica a oportunidade de montar uma copiadora em frente a uma universidade; outro identifica uma oportunidade de colocar um novo produto eletrônico no mercado mundial, realizando análises do ambiente global do setor, criando planos de negócio, interagindo com investidores etc. Observe-se que o segundo articula a competência de identificação e exploração 
de oportunidades num contexto bem mais sofisticado que o primeiro. Estudos na perspectiva de competências empreendedoras raramente realizam tal recorte no prisma da complexidade, essencial para caracterizar a competência empreendedora.

À guisa de síntese, este trabalho discute o uso que se vem fazendo do conceito de competências no campo de empreendedorismo. Após revisar estudos abordando a noção de competência em seu mainstream na área de negócios notadamente, o campo de gestão de pessoas - volta-se à análise do uso que se faz do conceito de competências empreendedoras. Observa-se que, neste campo, frequentemente se tomam noções como atitudes, traços de personalidade ou valores pessoais como sinônimos de competência. Tal nivelamento pode obscurecer o entendimento das pesquisas realizadas sobre o tema de competências empreendedoras. Como sugestão, propõe-se a revisão da terminologia adotada em estudos desta natureza, ou a apropriação do tema competências em linha com a acepção que vem recebendo na literatura especializada, a saber, como contribuição e entrega. De outro lado, recomenda a incorporação do conceito de complexidade como variável importante para caracterizar 0 escopo da competência empreendedora.

\section{REFERÊNCIAS}

ANTONELLO, C. S. A metamorfose da aprendizagem organizacional: Uma revisão crítica. In: RUAS, R. L.; ANTONELLO, C. S.; BOFF, L. H. (Org.). Os novos horizontes da gestão: aprendizagem organizacional e competências. Porto Alegre: Bookman, 2005, p. 12-33.

BANDURA, A. Social foundations of thought and action: a social cognitive theory. Englewood Cliffs, NJ: Prentice-Hall, 1986

BARINI FILHO, U. Transmissão da competência empreendedora: Um estudo de casos múltiplos. 2008. Tese de (Doutorado em Administração) - Universidade de São Paulo, 2008.

BARON, R. A.; SHANE, S. A. Empreendedorismo: Uma visão do processo. São Paulo: Thomson Learning, 2007.

BERGAMINI, C. W. Motivação nas organizações. 4. ed. São Paulo: Atlas, 1997.

BERNARDI, L. A. Manual de empreendedorismo e gestão: fundamentos, estratégias e dinâmicas. São Paulo: Atlas, 2003. 


\section{BITENCOURT, C. C. Gestão de competências e aprendizagem nas} organizações. São Leopoldo: Unisinos, 2005.

BOYATIZIS, R. Beyond Competence: the choice to be a leader. Human Resource Management Review. v. 3, n.1, p. 1-14, 1993.

BRANDÃO, H. P.; GUIMARÃES, T. A. Gestão de competências e gestão de desempenho: tecnologias distintas ou instrumentos de um mesmo construto? In: In: ENCONTRO NACIONAL DA ASSOCIAÇÃO NACIONAL DE PÓS-GRADUAÇÃO E PESQUISA EM ADMINISTRAÇÃO, 23, 1999, Foz do Iguaçu. Anais...Rio de Janeiro: Anpad, 1999.

CABRAL, R. M. A construção das competências de empreendedores líderes do segmento de confecções do Arranjo Produtivo Local do Agreste Pernambucano. In: ENCONTRO NACIONAL DA ASSOCIAÇÃO NACIONAL DE PÓS-GRADUAÇÃO E PESQUISA EM ADMINISTRAÇÃO, 32, 2008, Rio de Janeiro. Anais...Rio de Janeiro: Anpad, 2008. CARRIER, C. Intrapreneurship in small business: an exploratory study. Entrepreneurship Theory and Practice, v. 21, n. 1, p. 5-20, 1996.

CHEETHAM, G.; CHIVERS, G. Towards a holistic of professional competence. Journal of European Industrial Training, v. 20, n. 5, p. 20-30, 1996.

The reflective (and competent) practitioner: a model of professional competence which seeks to harmonize the refletive practitioner and competencebased approaches. Journal of European Industrial Training, v. 22, n. 7, p. 267276, 1998.

COOLEY, L. Entrepreneurship training and the strengthening of entrepreneurial performance. Final Report. Contract No. DAN-5314-C-00-3074-00. Washington: USAID, 1990.

DIAS, T. R. F. V.; NARDELLI, P. M.; VILAS BOAS, A. As. competências empreendedoras: um estudo sobre os empreendedores ganhadores do prêmio TOP Empresarial. In: ENCONTRO DE ESTUDOS SOBRE EMPREENDEDORISMO E GESTÃO DE PEQUENAS EMPRESAS, 5, 2008. São Paulo. Anais... São Paulo/SP: EGEPE, 2008.

DOLABELA, F. Oficina do empreendedor. São Paulo: Cultura, 1999.

DORNELAS, J. C. A. Empreendedorismo na prática: mitos e verdades do empreendedor de sucesso. Rio de Janeiro: Elsevier, 2007.

DUTRA, J. S. et al. Absorção do conceito de Competência em Gestão de Pessoas: 
A Percepção dos Profissionais e as orientações Adotadas pelas Empresas. In: ENCONTRO NACIONAL DA ASSOCIAÇÃO NACIONAL DE PÓS-GRADUAÇÃO E PESQUISA EM ADMINISTRAÇÃO, 30, 2006, Salvador. Anais...Rio de Janeiro: Anpad, 2006.

DUTRA, J. S. Gestão por competências. São Paulo: Gente, 2001

Competências: conceitos e instrumentos para a gestão de pessoas na empresa moderna. São Paulo: Atlas, 2004.

FERNANDES, B. H. R.; COMINI, G. Limitações na estruturação de modelos de gestão por competências: uma análise de organizações líderes em diversos setores. In: ENCONTRO NACIONAL DA ASSOCIAÇÃO NACIONAL DE PÓS-GRADUAÇÃO E PESQUISA EM ADMINISTRAÇÃO, 32, 2008, Rio de Janeiro. Anais...Rio de Janeiro: Anpad, 2008

FEUERSCHÜTTE, S. G.; ALPERSTEDT, G. D. Empreendedorismo e competência: um ensaio sobre a complementaridade e a convergência dos construtos. In: ENCONTRO NACIONAL DA ASSOCIAÇÃO NACIONAL DE PÓS-GRADUAÇÃO E PESQUISA EM ADMINISTRAÇÃO, 32, 2008, Rio de Janeiro. Anais...Rio de Janeiro: Anpad, 2008.

FEUERSCHÜTTE, S. G.; GODOI, C. K. Competências empreendedoras: um estudo historiográfico no setor hoteleiro. In: ENCONTRO NACIONAL DA ASSOCIAÇÃO NACIONAL DE PÓS-GRADUAÇÃO E PESQUISA EM ADMINISTRAÇÃO, 31, 2007, Rio de Janeiro. Anais...Rio de Janeiro: Anpad, 2007.

FILION, L. J. Empreendedorismo: empreendedores e proprietários-gerentes de pequenos negócios. Revista de Administração, São Paulo, v. 34, n. 2, p. 5-28, abr/jun, 1999.

FILION, L. J. O planejamento do seu sistema de aprendizagem empresarial: Identifique uma visão e avalie o seu sistema de relações. Revista de

Administração de Empresas, São Paulo, v. 31, n. 3, p.63-71, jul/set, 1991.

FLEURY, A.; FLEURY, M. T. L. Estratégias empresariais e formação de

competências: um quebra-cabeça caleidoscópico da indústria brasileira. 3. ed. São Paulo: Atlas, 2004.

FONSECA, F. R. B. et al. Competências empreendedoras como atributos geradores de valor: um estudo de caso no setor de base tecnológica. In: ENCONTRO NACIONAL DE ESTUDOS DA ENGENHARIA DE PRODUÇÃO, 26, 2006. Fortaleza. Anais... Fortaleza/CE: ENEGEPE, 2006.

GEFROY, F.; TIJOU, R. Le management des competences dans les enterprises 
europénnes: les différentes approaches. Paris: INSEP Consulting, 2002.

GRANOVETTER, M. Economic action and social structure: the problem of embeddedness. American Journal of Sociology, Chicago, v. 91, n. 3, p. 481-510, nov. 1985.

HONMA, E. T. Competências empreendedoras: estudo de casos múltiplos no setor hoteleiro em Curitiba. 2007, 180 f. Dissertação (Mestrado em Administração), Universidade Federal do Paraná, Curitiba, 2007

KETS DE VRIES, M. F. R. Liderança na empresa: como o comportamento dos líderes afeta a cultura interna. São Paulo: Atlas, 1997.

LE BOTERF, G. Desenvolvendo a competência dos profissionais. Porto Alegre: Artmed, 2003.

LEIRIA, A. M. L. As competências do empresário da empresa de pequeno porte. 2002, Porto Alegre, Dissertação (Mestrado em Administração) Programa de PósGraduação e Pesquisas em Administração, Universidade Federal do Rio Grande do Sul, Porto Alegre, 2002.

MAMEDE, M. I. B.; MOREIRA, M. Z. Perfil de competências empreendedoras dos investidores portugueses e brasileiros: um estudo comparativo na rede hoteleira do Ceará. In: In: ENCONTRO NACIONAL DA ASSOCIAÇÃO NACIONAL DE PÓSGRADUAÇÃO E PESQUISA EM ADMINISTRAÇÃO, 29, 2005, Brasília. Anais...Rio de Janeiro: Anpad, 2005

MAN, T. W. Y.; LAU, T. Entrepreneurial competencies of SME owner/managers in the Hong Kong services sector: a qualitative analysis. Journal of Enterprising Culture, v. 8, n. 3, p. 235-254., Sept. 2000,

McCLELLAND, D. C. A sociedade competitiva: realização e progresso social. Rio de Janeiro: Expressão e Cultura, 1972.

MINTZBERG, H.; AHLSTRAND, B.; LAMPEL, J. Safári de estratégia: um roteiro pela selva do planejamento estratégico. Porto Alegre: Bookman, 2000.

MORALES, S. A. Relação entre competências e tipos psicológicos junguianos. Florianópolis, 2004. 199 f. Tese (Doutorado em Engenharia da Produção) Programa de Pós-Graduação em Engenharia de Produção, Universidade Federal de Santa Catarina, Florianópolis, 2004.

MOURA, M. C. C.; BIENCOURT, C. C. A articulação entre estratégia e o desenvolvimento de competências gerenciais. RAE-Eletrônica, v. 5, n. 1, Art. 3, 
jan/jun. 2006.

PAIVA JÚNIOR, F. G.; et al. A contribuição das competências empreendedoras para a formação de dirigentes em sistemas de incubação. In: ENCONTRO NACIONAL DE ESTUDOS DA ENGENHARIA DE PRODUÇAึ̃O, 26, 2006. Fortaleza. Anais... Fortaleza/CE: ENEGEPE, 2006.

PAIVA JÚNIOR, F. G.; FERNANDES, N. C. M.; ALMEIDA, L. F. L. O capital social da empresa de base tecnológica expandida pela relacionalidade do empreendedor. In: ENCONTRO NACIONAL DE ESTUDOS DA ENGENHARIA DA PRODUÇÃO, , 26, 2006. Fortaleza. Anais... Fortaleza/CE: ENEGEPE, 2006.

PAIVA JÚNIOR, F. G.; LEÃO, A. L. M. de S. MELLO, S. C. B. Competências empreendedoras em comportamentos de dirigentes de êxito socialmente reconhecido. In: ENCONTRO NACIONAL DA ASSOCIAÇÃO NACIONAL DE PÓSGRADUAÇÃO E PESQUISA EM ADMINISTRAÇÃO, 27, 2003, Atibaia. Anais...Rio de Janeiro: Anpad, 2003.

PARDINI, D. J.; BRANDÃO, M. M.; SOUKI, G. Q. Competências empreendedoras e sistema de relações sociais: a dinâmica dos construtos na decisão de empreender nos serviços de fisioterapia. Revista de Negócios. Blumenau/SC; v. 13, n. 1, p. 2844, jan/mar. 2008.

PERRENOUD, P. Construir as competências desde a escola. Porto Alegre: Artes Médicas Sul, 1999.

PINCHOT III, G. Intrapreneuring: Por que você não precisa deixar a empresa para tornar-se um empreendedor. São Paulo: Harbra, 1989.

RUAS, R. Gestão por competências: uma contribuição à estratégia das organizações. In: RUAS, R.; ANTONELLO, C. S.; BOFF, L. H. (Org.). Os novos horizontes da gestão: a aprendizagem organizacional e competências. Porto Alegre: Bookman, 2005. p. 34-54.

RUAS, R. et al. O conceito de competência de A a Z:análise e revisão nas principais publicações nacionais entre 2000 e 2004. In: ENCONTRO NACIONAL DA ASSOCIAÇÃO NACIONAL DE PÓS-GRADUAÇÃO E PESQUISA EM ADMINISTRAÇÃO, 29, 2005, Brasília. Anais...Rio de Janeiro: Anpad, 2005

RUAS, R. et al. Gestão por competências: revisão de trabalhos acadêmicos no Brasil no período 2000 a 2008. Working paper, 2009.

SANDBERG, J. Understanding Human Competence at Work: an interpretative approach. Academy of Management Journal, Feb. 2000. 
SNELL, R.; LAU, A. Exploring local competences salient for expanding small business. Journal of Management Development, v. 13, n.4, 1994.

SPENCER, L.; SPENCER, S. Competence at work: models for superior performance. New York: John Wiley e Sons, 1994.

SVEIBY, K. E. A nova riqueza das organizações. Rio de Janeiro: Campus, 1998.

SWIERINGA, J.; WIERDSMA, A. La organización que aprende. Buenos Aires: 1992.

ZARIFIAN, P. Objetivo competência: por uma nova lógica. São Paulo: Atlas, 2001. 